\title{
Correction to: Efficient Algorithm for Identification and Cache Based Discovery of Cloud Services
}

\section{Abdul Quadir Md ${ }^{1}$ (D) Vijayakumar Varadarajan ${ }^{1} \cdot$ Karan Mandal $^{1}$}

Published online: 24 May 2019

(C) Springer Science+Business Media, LLC, part of Springer Nature 2019

\section{Correction to: Mobile Netw Appl https://doi.org/10.1007/s11036-019-01256-0}

The original version of this article unfortunately contained a mistake in the author group section. Author "V. Varadarajan" should be expanded to "Vijayakumar Varadarajan".

The original article has been corrected.

Publisher's Note Springer Nature remains neutral with regard to jurisdictional claims in published maps and institutional affiliations.

The online version of the original article can be found at https://doi.org/ 10.1007/s11036-019-01256-0

$\triangle$ Abdul Quadir Md

abdulquadir.md@vit.ac.in

Vijayakumar Varadarajan

vijayakumar.v@vit.ac.in

Karan Mandal

karan.mandal2017@vitstudent.ac.in

1 School of Computing Science and Engineering, Vellore Institute of Technology (VIT University), Chennai, Tamil Nadu 600127, India 